\title{
A case of hypomelanosis of Ito accompanied by unilateral abnormal limb overgrowth and delayed speech
}

\author{
(1) Mustafa Ozcetin, ${ }^{1}$ (D) Ayse Kilic, ${ }^{1}$ (i) Yakup Cag, ${ }^{2}$ (i) Fuat Bilgili,, (i) Busra Aksoy ${ }^{1}$ \\ ${ }^{1}$ Department of Pediatrics, Istanbul University Istanbul Faculty of Medicine, Istanbul, Turkey \\ ${ }^{2}$ Department of Pediatrics, Dr. Lutfi Kirdar Kartal Training and Research Hospital, Istanbul, Turkey \\ ${ }^{3}$ Department of Orthopedics and Traumatology, Istanbul University Istanbul Faculty of Medicine, Istanbul, Turkey
}

\begin{abstract}
Hypomelanosis of Ito $(\mathrm{HI})$ is characterized by unilateral or bilateral hypopigmented skin lesions and usually presents as a multisystemic disorder. Skin lesions may develop in different textures, such as linear, whorled, or patchy, and are often accompanied by abnormalities of the central nervous system, skeletal system, eyes, and teeth. HI is associated with sporadic gene mutations but not gender. Presentation of the current case may be of use in reminding practitioners of the common extracutaneous findings of $\mathrm{HI}$, along with some rare manifestations, such as delayed speech and asymmetric limb growth.
\end{abstract}

Keywords: Delayed speech; hypomelanosis of Ito; limb asymmetry.

Cite this article as: Ozcetin M, Kilic A, Cag Y, Bilgili $F$, Aksoy B. A case of hypomelanosis of Ito accompanied by unilateral abnormal limb overgrowth and delayed speech. North Clin Istanb 2020;7(1):71-73.

- $y$ ypomelanosis of Ito (HI) was first described by 1 Minor Ito in 1952 as incontinentia pigmenti achromians', a mosaic cutaneous disorder $[1,2]$. HI is the third most common neurocutaneous disorder following neurofibromatosis and tuberous sclerosis [2]. Pigmented lesions may be discernible at birth, although they can become accentuated during childhood as well. A wide variety of phenotypes are seen depending on the underlying mutations. The skin findings are characterized by hypopigmented lesions following the Blaschko lines, as do several other congenital and acquired dermatological conditions. These lines form an ' $\mathrm{S}$ ' shape over the trunk, a' $V$ ' shape over the back, a linear pattern over the limbs, and a wavy pattern on the head; they are thought to reflect the previous migration routes of embryonic cells [3]. Hypomelanosis of Ito can present with characteristic solitary, whorl-like, linear, or patchy skin lesions follow- ing the Blaschko lines, but it can also appear as a part of a complex malformation syndrome accompanied by extracutaneous findings [1-4]. In fact, these extracutaneous manifestations are seen in $76 \%$ to $94 \%$ of cases and frequently involve the central nervous system, musculoskeletal system, and eyes [2]. Asymmetric hypertrophic overgrowth has also been reported [5]. Herein, we report on a case of $\mathrm{HI}$ accompanied by unilateral abnormal limb overgrowth and delayed speech.

\section{CASE REPORT}

A 5.5-year-old girl was brought to our hospital with a complaint of disproportionate overgrowth and lengthening of the right leg accompanied by marked hypopigmented lesions over the trunk and legs, which reportedly had become noticeable by 2 -weeks postpartum and grad-

Received: July 24, 2017 Accepted: October 10, 2018 Online: December 03, 2018

Correspondence: Dr. Mustafa OZCETIN. Istanbul Universitesi, Istanbul Tip Fakultesi, Cocuk Sagligi ve Hastaliklari Anabilim Dali, 34680 Istanbul, Turkey.

Tel: +90 5327248939 e-mail: mozcetin@gmail.com

(c) Copyright 2020 by Istanbul Provincial Directorate of Health - Available online at www.northclinist.com 


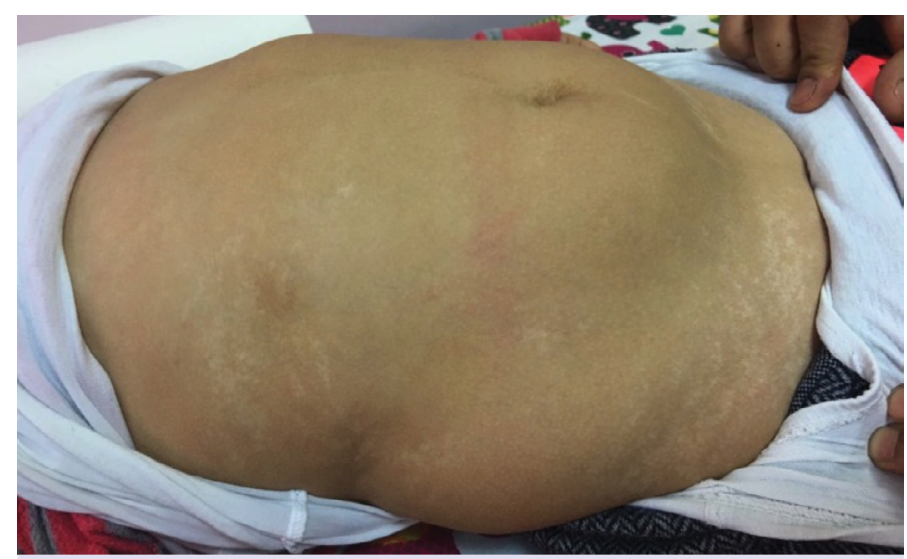

FIGURE 1. Hypopigmentation following the lines of Blaschko in a patient with hypomelanosis of Ito



FIGURE2. Linear hypopigmented patches located in the front aspect of the leg.

ually increased and spread. She was born to non-consanguineous parents and had been under monitoring for delayed speech. On examination, her height and weight were $110 \mathrm{~cm}\left(10^{\text {th }}\right.$ to $25^{\text {th }}$ percentile $)$ and $23 \mathrm{~kg}\left(75^{\text {th }}\right.$ to

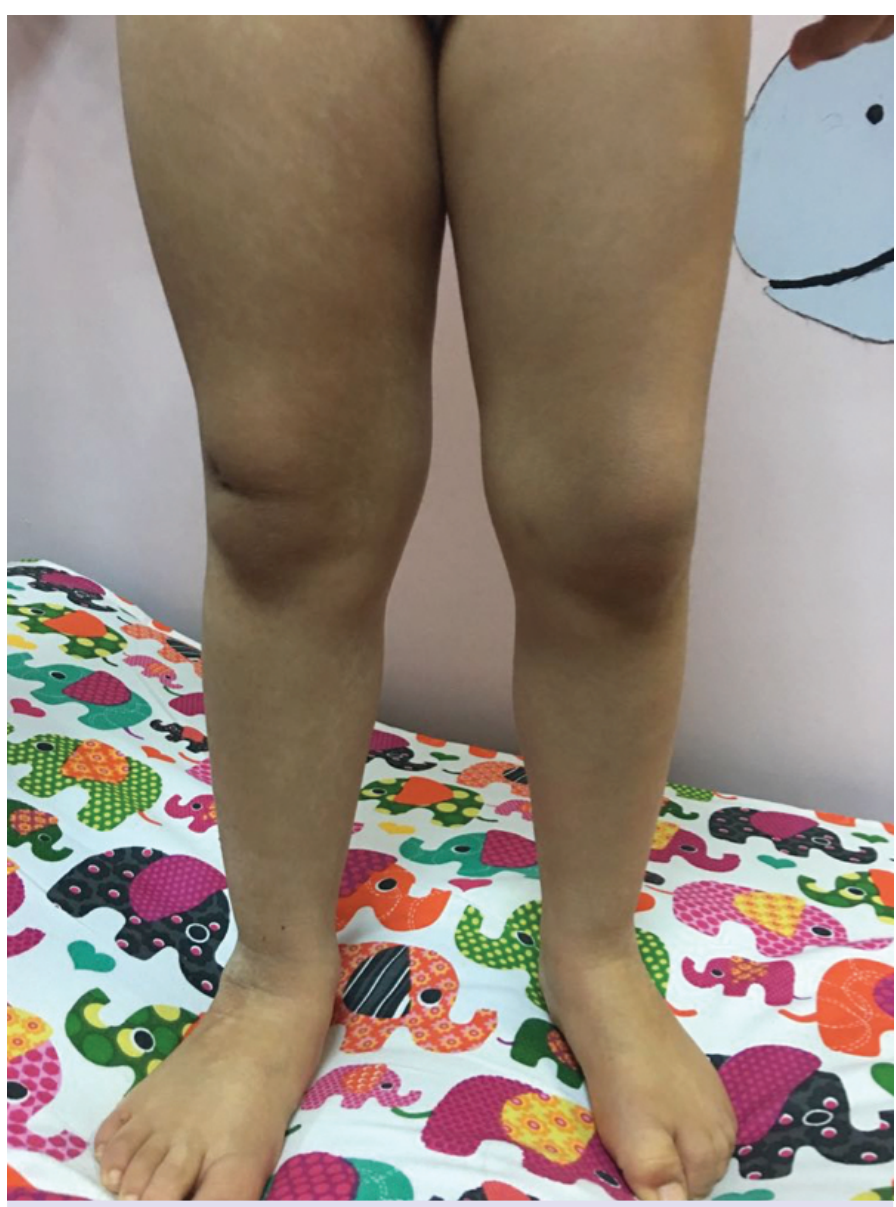

FIGURE 3. Body asymmetry with the right leg thicker and longer than the left leg.

$90^{\text {th }}$ percentile), respectively. The dermatological examination was remarkable for hypopigmented patches following the Blaschko lines over the trunk and both legs, more prominently on the right leg (Fig. 1, 2), which was thicker and longer $(\sim 2 \mathrm{~cm})$ than the left (Fig. 3). Apart from these findings, the systemic examinations, routine haemogram and biochemical tests, and magnetic resonance scans of the cranium and lower extremities were normal. When the Denver Developmental Screening Test was administered for speech delay, it was graded as 'delayed', correlating with the age of 3.5 years. After consultation with the dermatology department, a skin biopsy was considered unnecessary.

\section{DISCUSSION}

Although HI was initially defined as only a cutaneous disease, several reports of extracutaneous involvement led to a tendency to regard it more as a neurocutaneous syndrome [2]. A wide variety of HI phenotypes can be 
seen depending on the underlying mutation. Skin manifestations are characterized by hypopigmented lesions following the Blaschko lines. The streaks and whorls of these lesions may be present at birth or appear later during childhood, especially in light-skinned individuals. Hypomelanosis of Ito is associated with sporadic gene mutations without any predilection for gender [6]. Histological studies are of limited diagnostic value due to the lack of characteristic variation although an examination of the hypopigmented lesions of some cases demonstrated a decrease in the size and number of melanosomes in the basal layer of the epidermis [7]. In our case, the hypopigmented lesions were typical, following the Blaschko lines, and a skin biopsy was not carried out because of the unlikelihood of a typical histopathological finding.

Hypomelanosis of Ito can be accompanied by abnormalities of the central nervous system, as well as others involving the musculoskeletal system, eyes, hair, and teeth. A wide variety of coexisting conditions has been reported in the literature, including mental and motor retardation, hypotonia, hyperkinesia, ataxia, epilepsy, impaired or delayed speech, facial and limb asymmetry, and kyphoscoliosis. Given this wide range of accompanying abnormalities, Ruiz-Maldonado et al. [8] proposed a set of HI diagnostic criteria in 1992. In addition to congenital or early acquired nonhereditary cutaneous hypopigmented streaks or patches present on at least two parts of the body, the major criteria included coexisting abnormalities of the nervous system or musculoskeletal system, while the minor criteria included congenital malformations involving other systems or chromosomal anomalies. The diagnosis can be made when the presence of skin involvement is accompanied by two major criteria or one major criterion plus two minor criteria. In our case, the cutaneous involvement was accompanied by delayed speech and overgrowth in the right leg. In the absence of a histological assessment, the terms 'overgrowth' or 'abnormal growth' are more appropriate terms than 'hyperplasia' (abnormal cell proliferation) or 'hypertrophy' (abnormal growth in the size of the existing cells) [5]. Reports on the association between HI and asymmetric limb overgrowth are rare in the literature, and a systematic study is still lacking.
There is no specific treatment for HI. It is suggested that should suspected skin lesions appear, a comprehensive systemic examination should be carried out. Infants, especially girls, should be assessed at least every three months in the first year of life concerning the developmental progression of the lesions, as well as of head growth and mental development [9]. The presentation of this case should provide a useful reminder of the common extracutaneous findings of HI, as well as some of its rare manifestations, such as delayed speech and asymmetric limb growth.

Informed Consent: Written informed consent was obtained from the patient for the publication of the case report and the accompanying images.

Conflict of Interest: No conflict of interest was declared by the authors.

Financial Disclosure: The authors declared that this study has received no financial support.

Authorship Contributions: Concept - MO; Design - YC; Supervision - AK; Fundings - MO, FB; Materials - BA; Data collection and/ or processing - $\mathrm{MO}, \mathrm{BA}$; Analysis and/or interpretation - $\mathrm{AK}, \mathrm{FB}$; Literature review - BA, YC; Writing - MO, YC; Critical review - MO.

\section{REFERENCES}

1. Ruggieri M, Praticò AD. Mosaic neurocutaneous disorders and their causes. Semin Pediatr Neurol 2015;22:207-33. [CrossRef]

2. Ruggieri M, Pavone L. Hypomelanosis of Ito: clinical syndrome or just phenotype? J Child Neurol 2000;15:635-44. [CrossRef]

3. Happle R, Assim A. The lines of Blaschko on the head and neck. J Am Acad Dermatol 2001;44:612-5. [CrossRef]

4. Glover MT, Brett EM, Atherton DJ. Hypomelanosis of Ito: spectrum of the disease. J Pediatr 1989;115:75-80. [CrossRef]

5. Pavone V, Signorelli SS, Praticò AD, Corsello G, Savasta S, Falsaperla $\mathrm{R}$, et al. Total Hemi-overgrowth in Pigmentary Mosaicism of the (Hypomelanosis of) Ito Type: Eight Case Reports. Medicine (Baltimore) 2016;95:e2705. [CrossRef]

6. Molho-Pessach V, Schaffer JV. Blaschko lines and other patterns of cutaneous mosaicism. Clin Dermatol 2011;29:205-25. [CrossRef]

7. Küster W, König A. Hypomelanosis of Ito: no entity, but a cutaneous sign of mosaicism. Am J Med Genet 1999;85:346-50. [CrossRef]

8. Ruiz-Maldonado R, Toussaint S, Tamayo L, Laterza A, del Castillo V. Hypomelanosis of Ito: diagnostic criteria and report of 41 cases. Pediatr Dermatol 1992;9:1-10. [CrossRef]

9. Ream M. Hypomelanosis of Ito. In: Neurocutaneous syndromes, Handbook of clinical neurology, Islam MP, Roach ES, editors. Vol. 132. $1^{\text {st }}$ ed.Amsterdam: Elsevier; 2015. p. 281-7. [CrossRef] 